\title{
Kejadian Kecacingan pada Siswa Sekolah Dasar Negeri Kecamatan Rumbai Pesisir Pekanbaru
}

\author{
The Helminthiasis on The State Elementary School Student on Kecamatan \\ Rumbai Pesisir Pekanbaru
}

\section{Sri Kartini}

Universitas Abdurrab Pekanbaru

\begin{abstract}
ABSTRAK
Penyakit kecacingan masih menjadi masalah kesehatan. Penyakit ini terutama diderita oleh anak-anak. Pada kondisi kecacingan ringan tidak menimbulkan gejala, pada kondisi berat dapat menimbulkan manifestasi usus, malaise, gangguan perkembangan kognitif, terganggunya perkembangan fisik dan anemia. Penelitian ini bertujuan untuk mengethui proporsi dan faktor-faktor yang berhubungan dengan kejadian kecacingan Soil Transmitted Helminth (STH) yaitu kebiasaan mencuci tangan, kebersihan kuku, ketersediaan jamban, jenis lantai rumah, ketersediaan air bersih di rumah,ketersediaan tempat sampah, kebiasaan bermain di tanah,kebiasaan menggunakan alas kaki, ketersediaan Sarana Pembuangan Air Limbah (SPAL), pekerjaan ibu, pekerjaan ayah, jenis kelamin dan minum obat cacing. Penelitian ini bersifat kuatitatif analitik observasional dengan studi penampang analitik. Populasi adalah seluruh siswa SD Negeri Kecamatan Rumbai Pesesir sebanyak 2610 orang dan sampel 240 orang. Sampling yang digunakan adalah systematic random sampling. Analisis data menggunakan uni regresi linier ganda. Hasil penelitian diperoleh proporsi kecacingan 16,3\%, jenis Ascaris lumbricoides 13,0\%, Trichuiris trichiura 2,5\% dan cacing Tambang 0,8\%.Variabel yang berhubungan dengan kecacingan: minum obat cacing (POR:11,143; 95\%CI: 4,179-31,886), kebiasaan mencuci tangan (POR:5,366; 95\%CI: 2,186-13,172), ketersediaan SPAL (POR:2,615; 95\%CI: 1,195-6,787), kebersihan kuku (POR: 2,378; 95\%CI : 1,300-7,227).
\end{abstract}

Kata Kunci: Kecacingan, minum obat cacing, kebiasaan mencuci tangan, ketersediaan SPAL, kebersihan kuku.

\section{ABSTRACT}

Helminthiasis remains a health problem. This disease mostly suffered by children. Mild helminthiasis cause no symptoms, but in severe conditions can cause intestinal problems such as diarrhea and abdominal pain, malaise, decreasing cognitive and physical development, and anemia.The purpose of this study was to determine the proportion of helminthiasis and factors associated with helminthiasis i.e the habit of hand washing, nail hygiene, availability of latrines, type of floor of the house, the availability of clean water in the house, the availability of trash, a habit of playing in land, the habit of using footwear, availability of Waste Water Disposal Facility, mother's occupation, father's occupation, sex and drinking-worming in elementery school students. This study was observasional analytic study with crossectional approach. The population were 2610 students of state elementary school in Kecamatan Rumbai Pesisir. As many as 240 students obtained a sample by using systematic random sampling The date was analaized with Multiple linear regression. The results showed the proportion of helminthiasis incidence was $16.3 \%$,which ascariasis incidence $12.9 \%$, trichuriasis $2.5 \%$ and hookworm infection $0.8 \%$. The Variables that significantly related to the incidence of helminthiasis were taking anthelmintics (POR: 11.143; 95\% CI: 4.179 to 31.886), handwashing (POR: 5.366; 95\% CI: 2.186 to 13.172), the availability of SPAL (POR: 2.615; 95\% CI: 1.195 to 6.787) and nail hygiene (POR: 2.378; 95\% CI: $1.300-7.227$ ).

Keywords: Helminthiasis, taking anthelmintics, handwashing, availability SPAL, nail hygiene.

\section{PENDAHULUAN}

Di Indonesia masih banyak penyakit yang merupakan masalah kesehatan, salah satu diantaranya ialah cacing perut yang ditularkan melalui tanah . Cacing ini dapat mengakibatkan menurunnya kondisi kesehatan, gizi, kecerdasan dan produktivitas penderitanya sehingga secara ekonomi banyak menyebabkan kerugian, sehingga menurunkan kualitas sumber daya manusia (Depkes RI,2006 ${ }^{\mathrm{a}}$ ).

Diantara cacing perut terdapat sejumlah spesies yang ditularkan melalui tanah (Soil Transmitted

\footnotetext{
${ }^{1}$ Alamat Korespodensi:_Sri Kartini, Universitas Abdurrab Pekanbaru, Email: sri.kartini@univrab.ac.id
} 
Helminth). Namun yang terpenting adalah cacing gelang (Ascaris lumbricoides), cacing cambuk (Trichuris trichiura) dan cacing tambang (Necator americanus dan Ancylostoma duodenale) karena jenis cacing ini yang paling banyak menginfeksi manusia ( Depkes RI, 2006 ${ }^{\mathrm{a}}$ ).

Infeksi kecacingan adalah masuknya bibit penyakit yang disebabkan oleh mikroorganisme (cacing) dalam tubuh manusia dan berkembang biak sehingga menimbulkan penyakit (Entjang,2003) Infeksi kecacingan dinyatakan positif apabila ditemukan telur cacing minimal satu jenis cacing dalam spesimen yang diperiksa.

Infeksi cacing STH banyak terdapat pada anak usia Sekolah Dasar (SD). Anak dengan infeksi kecacingan ringan biasanya tidak menimbulkan gejala. Akan tetapi infeksi berat dapat menimbulkan manifestasi usus (diare dan sakit pert), malaise umum, perkembangan kognitif yang lemah, terganggunya perkembangan fisik dan anemia (WHO, 2013).

Lebih dari 1,5 miliar orang atau $24 \%$ dari populasi dunia terinfeksi cacing STH dan lebih dari 880 juta anak membutuhkan pengobatan penyakit akibat parasit ini (WHO, 2013). Di Indonesia angka kejadian infeksi cacing pada anak sekolah dasar berkisar antara 2,7 - 60,7\% (Depkes RI, 2009).

Hasil pemeriksaan tinja oleh Dinkes Provinsi Riau tahun 2011 pada siswa SD di Kabupaten Siak dari 201 siswa ditemukan sebanyak 19 sampel (9,5\%) positif terinfeksi cacing STH. Di Kota Dumai dari 200 siswa yang sampel tinjanya diperiksa sebanyak 33 sampel (16,5\%) positif terinfeksi cacing STH.

Data Dinkes Kota Pekanbaru tahun 2012 menunjukkan kasus kecacingan dari 20 puskesmas tercatat 2285 kasus, dimana 225 kasus terdapat di puskesmas Rumbai Pesisir. Belum diketahui berapa persentase kecacingan pada anak SD di kecamatan tersebut. Penelitian Irman (2013) di SDN 40 Kecamatan Rumbai Pesisir dari 70 siswa sebanyak $38,6 \%$ terinfeksi cacing STH. Menurut Kepmenkes. RI No.424/MENKES/SK/VI/2006 tentang Pedoman Pengendalian Cacingan bahwa salah satu tujuan programnya adalah menurunkan prevalensi kecacingan menjadi $<10 \%$ pada tahun 2010 dengan salah satu sasaranya adalah anak sekolah dasar (Depkes. RI,2006 ${ }^{\mathrm{b}}$ ).

Faktor-faktor yang berhubungan dengan infeksi cacing pada anak erat hubungannya dengan hygiene dan sanitasi (Safar, 2009).faktor tersebut diantaranya meliputi ketersediaan air bersih, jamban, SPAL, jenis lantai, tempat sampah, kebersihan kuku, penggunaan alas kaki, kebiasaan bermain di tanah dan kebiasaan mencuci tangan. Selain itu pekerjaan ibu, pekerjaan ayah, jenis kelamin dan minum obat cacing juga mempengaruhi kejadian infeksi cacing pada anak sekolah dasar.
Anak usia sekolah dasar merupakan aset sumber daya manusia masa depan bangsa yang harus dijaga kualitasnya. Salah satu diantaranya anak harus dijaga dari penyakit infeksi kecacingan. Menurut Arimbi (2010) infeksi cacing berdampak buruk terhadap perkembangan kesehatan dan mental bahkan dapat menghambat tumbuh kembang anak, kecacatan dan kebutaan. Apabila hal ini terjadi pada anak sekolah dasar maka bangsa akan megalami kehilangan sumber daya manusia yang berkualitas.Tujuan penelitian ini adalah diketahuinya proporsi dan factor-faktor yang berhubungan dengan kejadian infeksi cacing STH pada siswa sekolah dasar Kecamatan Rumbai Pesisir Pekanbaru tahun 2014.

\section{METODE}

Jenis penelitian ini adalah Kuantitatif Analitik Observasional dengan desain Analytic Cross-sectional Study yang dilaksanakan di Sekolah Dasar Negeri Kecamatan Rumbai Pesisir Pekanbaru tahun 2014. Populasi dalam penelitian adalah siswa kelas I sampai $\mathrm{V}$ berjumlah 6110 orang. Perhitungan besar sampel dengan menggunakan rumus untuk desain Crossectional Study yaitu dengan nilai proporsi populasi hasil penelitian terdahulu (P0), nilai sesungguhnya dari proporsi populasi $(\mathrm{Pa})$. Menggunakan Tabel Simple Size for One-Simple Test of Proportional (Level of Significance 5\%; Power 90\%; Alternatif hypothesis:1side) diperoleh sampel sebanyak 240 responden. Teknik pengambilan sampel secara Sytematic Random Sampling. Variabel independen yang dikumpulkan adalah kebiasaan mencuci tangan, kebersihan kuku, ketersediaan jamban, jenis lantai rumah, ketersediaan air bersih di rumah,ketersediaan tempat sampah, kebiasaan bermain di tanah,kebiasaan menggunakan alas kaki, ketersediaan Sarana Pembuangan Air Limbah (SPAL), pekerjaan ibu, pekerjaan ayah, jenis kelamin dan minum obat cacing, variabel dependen adalah kecacingan. Data yang dikumpulkan adalah data primer dari semua variabel independen dengan memberikan kuesioner pada responden dan data pemeriksaan kecacingan menggunakan mikroskop. Analisis bivariat dilakukan dengan uji Chi-Square dan untuk analisis Multivariat dilakukan dengan uji Regresi Logistik Ganda.

\section{HASIL}

Proposi kecacingan pada siswa SD Negeri Kecamatan Rumbai Pesisir diperoleh sebesar 16,3\%, dimana siswa yang terinfeksi cacing jenis Ascaris lumbricoides sebesar 13,0\%, Trichuiris trichiura sebesar 2,5\% dan cacing Tambang sebesar 0,8\%.

Hasil uji bivariat terhadap 13 variabel, terdapat 7 variabel yang mempunyai hubungan signifikan dengan kejadian infeksi cacing yaitu kebiasaan mencuci tangan (pvalue $=0,001$ ) ,kebersihan kuku 
$($ pvalue $=0,001)$, kebiasaan bermain di tanah $(p v a l u e=$ $0,019)$, ketersediaan SPAL (pvalue $=0,005$ ),pekerjaan ibu $($ pvalue $=0,014)$, pekerjaan ayah $($ pvalue $=0,025)$ dan minum obat cacing (pvalue $=0,001$ ). Berdasarkan nilai POR maka Siswa yang tidak mempunyai kebiasaan mencuci tangan lebih berisiko 7 kali terinfeksi cacing dibandingkan siswa yang mempunyai kebiasaan mencuci tangan. Siswa yang mempunyai kuku kotor berisiko 4 kali terinfeksi cacing dibandingkan siswa yang mempunyai kuku bersih. Siswa yang mempunyai kebiasaan bermain di tanah lebih berisiko 2 kali terinfeksi cacing dibandingkan msiswa yang tidak mempunyai kebiasaan bermain di tanah. Siswa yang rumahnya tidak mempunyai ketersediaan SPAL lebih berisiko 3 kali terinfeksi cacing dibandingkan dengan siswa yang mempunyai ketersediaan SPAL. Siswa yang mempunyai ibu bekerja sebagai petani berisiko 3 kali terinfeksi cacing dibandingkan siswa yang ibunya bekerja bukan sebagai petani. Siswa yang mempunyai ayah bekerja sebagai petani berisiko 2,5 kali terinfeksi cacing dibandingkan siswa yang ayahnya bekerja bukan sebagai petani. Siswa yang tidak minum obat cacing dalam rentang 6 bulan berisiko 10,5 kali berisiko terinfeksi cacing dibandingkan siswa yang minum obat cacing dalam rentang 6 bulan (Tabel. 1)

Tabel 1

Kejadian Infeksi Cacing pada Siswa Sekolah Dasar Negeri Kecamatan Rumbai Pesisir Pekanbaru

\begin{tabular}{|c|c|c|c|c|c|c|c|c|}
\hline \multirow{3}{*}{$\begin{array}{c}\text { Variabel Independen dan } \\
\text { Kategori }\end{array}$} & \multicolumn{4}{|c|}{ Infeksi cacinng } & \multicolumn{2}{|c|}{ Jumlah } & \multirow{3}{*}{$\begin{array}{c}P \\
\text { value }\end{array}$} & \multirow{3}{*}{$\begin{array}{c}\text { POR } \\
(95 \% \mathrm{CI})\end{array}$} \\
\hline & \multicolumn{2}{|c|}{$\mathrm{Ya}$} & \multicolumn{2}{|c|}{ Tidak } & \multirow[t]{2}{*}{$\mathrm{N}$} & \multirow[t]{2}{*}{$(\%)$} & & \\
\hline & $\mathrm{n}$ & $(\%)$ & $\mathrm{N}$ & $(\%)$ & & & & \\
\hline \multicolumn{9}{|l|}{ Kebiasaan mencuci tangan } \\
\hline Tidak & 30 & $(31,3)$ & 66 & $(68,8)$ & 96 & $(100)$ & \multirow[t]{2}{*}{0,001} & 6,818 \\
\hline $\mathrm{Ya}$ & 9 & $(6,3)$ & 35 & $(93,8)$ & 144 & $(100)$ & & $(3,061-15,189)$ \\
\hline \multicolumn{9}{|l|}{ Kebersihan kuku } \\
\hline Kotor & 23 & $(30,3)$ & 53 & $(69,7)$ & 76 & $(100)$ & \multirow[t]{2}{*}{0,001} & 4,014 \\
\hline Bersih & 16 & $(9,8)$ & 148 & $(90,2)$ & 164 & $(100)$ & & $(1,922-8,173)$ \\
\hline \multicolumn{9}{|l|}{ Ketersediaan jamban } \\
\hline Tidak tersedia & 15 & $(23,4)$ & 49 & $(76,6)$ & 64 & $(100)$ & \multirow[t]{2}{*}{0,105} & 1,939 \\
\hline Tersedia & 24 & $(13,6)$ & 152 & $(86,4)$ & 176 & $(100)$ & & $(0,943-3,987)$ \\
\hline \multicolumn{9}{|l|}{ Jenis lantai rumah } \\
\hline Tanah,papan,kayu & 15 & $(20,8)$ & 57 & $(79,2)$ & 72 & $(100)$ & \multirow[t]{2}{*}{0,285} & 1,578 \\
\hline Ubin, keramik & 24 & $(14,3)$ & 144 & $(85,7)$ & 168 & $(100)$ & & $(0,773-3,225)$ \\
\hline \multicolumn{9}{|l|}{ Ketersediaan air bersih di rumah } \\
\hline Tidak tersedia & 13 & $(18,1)$ & 59 & $(81,9)$ & 72 & $(100)$ & \multirow[b]{2}{*}{0,760} & 1,203 \\
\hline Tersedia & 26 & $(15,5)$ & 142 & $(84,5)$ & 168 & $(100)$ & & $(0,579-2,501)$ \\
\hline \multicolumn{9}{|l|}{ Ketersedaan tempat sampah } \\
\hline Tidak terseda & 16 & $(17,8)$ & 74 & $(82,2$ & 90 & $(100)$ & \multirow[t]{2}{*}{0,752} & 1,194 \\
\hline Terseda & 23 & $(25,3)$ & 127 & $(84,7)$ & 150 & $(100)$ & & $(0,593-2,403)$ \\
\hline \multirow{2}{*}{\multicolumn{9}{|c|}{$\begin{array}{c}\text { Kebiasaan bermain di tanah } \\
\text { Ya }\end{array}$}} \\
\hline & & & & & & & & \\
\hline Tidak & 17 & $(26,2)$ & 48 & $(73,8)$ & 65 & $(100)$ & \multirow[t]{2}{*}{0,019} & 2,463 \\
\hline & 22 & $(12,6)$ & 153 & $(87,4)$ & 175 & $(100)$ & & $(1,210-6,016)$ \\
\hline Kebiasaanmenggunakan a & & & & & & & & \\
\hline kaki & 25 & $(21,0)$ & 94 & $(79,0)$ & 119 & $(100)$ & 0.071 & 2,033 \\
\hline Tidak & 14 & $(11,6)$ & 107 & $(88,4)$ & 121 & $(100)$ & & $(0,999-4,137)$ \\
\hline $\mathrm{Ya}$ & & & & & & & & \\
\hline Ketersediaan SPAL & & & & & & & & \\
\hline Tidak tersedia & 26 & $(24,1)$ & 82 & $(75,9)$ & 108 & $(100)$ & & 2,902 \\
\hline Tersedia & 13 & $(9,6)$ & 119 & $(40,2)$ & 132 & $(100)$ & 0,005 & $(1,409-5,979)$ \\
\hline Pekrjaan ibu & & & & & & & & \\
\hline Berisiko & 10 & $(33,3)$ & 20 & $(66,7)$ & 30 & $(100)$ & 0,014 & 3,121 \\
\hline Tidak & 29 & $(13,8)$ & 189 & $(86,2)$ & 210 & $(100)$ & & $(1,328-7,332)$ \\
\hline Pekerjaan Ayah & & & & & & & & \\
\hline Berisiko & 13,2 & $(28,3)$ & 33 & $(71,7)$ & 46 & $(100)$ & 0,025 & 2,545 \\
\hline Tidak & 6 & $(13,4)$ & 168 & $(86,6)$ & 194 & $(100)$ & & $(1,187-5,400)$ \\
\hline Jenis kelamin & & & & & & & & \\
\hline Laki-laki & 22 & $(21,2)$ & 82 & $(78,8)$ & 106 & $(100)$ & 0,104 & 1,878 \\
\hline Perempuan & 17 & $(12,5)$ & 119 & $(87,5)$ & 136 & $(100)$ & & $(0,940-3,756)$ \\
\hline Minum obat cacing & & & & & & & & \\
\hline$\geq 6$ bulan & 33 & $(32,4)$ & 69 & $(67,6)$ & 102 & $(100)$ & 0,001 & 10,522 \\
\hline$<6$ bulan & 6 & $(4,3)$ & 132 & $(95,7)$ & 138 & $(100)$ & & $4,204-26,331)$ \\
\hline
\end{tabular}


Hasil analisis multivariat dengan 8 kali pemodelan menunjukkan bahwa variabel yang berhubungan secara bermakna dengan kejadian infeksi cacing adalah minum obat cacing, kebiasaan mencuci tangan, ketersediaan SPAL, dan kebersihan kuku. Hasil analisis didapatkan bahwa variabel yang paling dominan berhubungan dengan kejadian infeksi cacing STH dengan nilai POR $=11,143$ (Tabel. 2)

Tabel 2.

Permodelan Multivariat Tahap Akhir

\begin{tabular}{|c|c|c|c|c|c|}
\hline \multirow[t]{2}{*}{ No } & \multirow[t]{2}{*}{ Variabel } & \multirow[t]{2}{*}{ p value } & \multirow[t]{2}{*}{ POR } & \multicolumn{2}{|c|}{$(95 \%$ CI $)$} \\
\hline & & & & Lower & Upper \\
\hline 1. & $\begin{array}{l}\text { Kebiasaan mencuci } \\
\text { tangan }\end{array}$ & 0,001 & 5,366 & 2,186 & 13,172 \\
\hline 2. & Kebersihan kuku & 0,010 & 2,378 & 1,300 & 7,227 \\
\hline 3 & Ketersediaan jamban & - & - & - & - \\
\hline 4 & Jenis lantai rumah & - & - & - & - \\
\hline 5 & $\begin{array}{l}\text { Kebiasaan bermain } \text { di } \\
\text { tanah }\end{array}$ & - & - & - & - \\
\hline 6 & $\begin{array}{l}\text { Kebiasaan menggunakan } \\
\text { alas kaki }\end{array}$ & - & - & - & - \\
\hline 7 & Ketersediaan SPAL & 0,018 & 2,615 & 1,195 & 6,787 \\
\hline 8 & Pekerjaan ibu & - & - & - & - \\
\hline 9 & Pekerjaan ayah & - & - & - & - \\
\hline 10 & Jenis kelamin & - & - & - & - \\
\hline 11. & Minum obat cacing & 0,001 & 11,143 & 4,179 & 31,886 \\
\hline
\end{tabular}

\section{PEMBAHASAN}

\section{Minum Obat Cacing}

Dalam penelitian ini minum obat cacing berhubungan sebab akibat dengan kejadian kecacingan pada siswa sekolah dasar. Siswa yang tidak minum obat cacing dalam rentang waktu 6 bulan dapat terkena 11 kali lebih besar kecacingan bila dibandingkan dengan siswa yang minum obat cacing dalam rentang 6 bulan. Pencegahan kecacingan disarankan oleh WHO difoluskan pada penduduk risiko tinggi. Pengobatan pada anak-anak diberikan apabila lebih dari $10 \%$ kejadian kecacingan (Chin,2012). Pemberian obat cacing pada setiap penderit dapat menyembuhkan penderita dengan tingkat kesembuhan 70-99\% (Depkes RI,2004). Pengobatan dengan cara minum obat cacing 6 bulan sekali didasarka pada siklus hidup cacing dari mulai masuknya telur hingga menjadi larva dan menginfeksi manusia. Hasil penelitian ini sejalan dengan penelitian Ginting (2009) dimana responden yang tidak minum obat cacing dalam rentang 6 bulan mengalami kecacingan.

\section{Kebiasaan Mencuci Tangan}

Siswa yang tidak mempunyai kebiasaan mencuci tangan dapat terkena 5 kali lebih besar kejadian kecacingan dibandingkan siswa yang mempunyai kebiasaan mencuci tangan. Siswa yang mempunyai kebiasaan mencuci tangan akan memungkinkan mengurangi terjadinya infeksi cacing.

Hasil penelitian ini sejalan dengan penelitian Babatunde (2013) pada anak sekolah dasar di Nigeria. Hasil tersebut menemukan adanya hubungan mencuci tangan sebelum makan dengan kecacingan. Hasil penelitian Mustakim (2013) terdapat hubungan anatara mencuci tangan dengan sabun dengan kecacingan pada siswa SD di Kabupaten Indra Giri Hilir. Mencuci tangan sebelum makan dan sesudah buang air besar menggunakan sabun merupakan salah satu upaya pencegahan kecacingan (KepMenkes RI,2006;Widodo,2013). Selama beraktifitas seperti bermain dan buang air besar anak biasa menyentuh tinjanya atau tanah yang mengandung telur cacing sehingga tangan dapat menularkan cacing apabila tidak dicuci sebulum makan karena telir cacing dapat tertelan memalui tangan tersebut.

\section{Ketersediaan Sarana Pembuangan Air Limbah (SPAL)}

Siswa yang rumahnya tidak mempunyai ketersediaan SPAL akan mempengaruhi 3 kali lebih besar kejadian infeksi cacing dibandingkan dengan siswa yang mempunyai ketersediaan SPAL. Hasil peneitian ini sesuai dengan penelitian Fitri (2012) pada siswa SD di Kecamatan Angola Kabupaten Tapanuli 
Selatan dimana terdapat hubungan antara ketersediaan SPAL dengan kecacingan. Air limbah rumah tangga dapat berasal dari buangan kamar mandi, dapur, air cuci pakaian dan lain-lain yang mingkin mengandung mikroorganisme patogen (Ehles dan Steel dalam Candra 2007). SPAL yang baik harus memenuhi syarat yaitu tidak mencemari sumber airminum, tidak mencemari air permukaan, tidak dihinggapi serangga penyebab penyakit, tertutup, tidak berbau dan mempunyai pembuangan diujung saluran (Notoatmodjo,2007) SPAL yang tidak dikelola dengan baik maka limbah akan menyebar di lingkungan sekitar dan menyebabkan tanak menjadi basah dan lembab. Kondisi ini akan menjadi media yang baik untuk cacing STH. Penularan dapat terjadi pada anak apabila menginjak tanah yang mengandung telur cacing tanpa menggunakan alas kaki.

\section{Kebersihan Kuku}

Siswa yang mempunyai kuku kotor mempengaruhi 2 kali terinfeksi cacing dibandingkan siswa yang mempunyai kuku bersih. Kebersiah kuku merupakansalah asu usaha untuk mencapai kebersihan diri. Kuku sebaiknya selalu dipotong pendek minimal sekali dalam seminggu. Kebiasaan menggigit kuku dan memasukkan jari ke dalam mulut pada anak-anak untuk memungkinkan penularan cacing dari kuku ke mulut. Penelitian ini sejalan dengan penelitan Ratag (2012) pada anak Sekolah Dasar di Kabupaten Kepualauan Sangie.

Dari impliksi keempat variabel yang mempunyai hubungan sebab akibat diatas, variabel minum obat cacing mempunyai kekuatan hubungan yang paling besar. Akan tetapi dalam usaha pencegahan dan pemberantasan infeksi cacing pengobatan bukanlah hal yang utama dilakukan karena pengobatan yang tidak diiringi dengan prilaku hidup bersih maka tidak optimal. Pencegahan dapat dilakukan dengan pemutusan daur hidup cacing lebih diutamakan yaitu dengan menjaga prilaku hidup bersih dan sehat yakni dengan membiasakan cuci tangan yang benar,menjaga kebersihan kuku, memenuhi ketersediaan SPAL. Apabila infeksi cacing yang dialami anak sudah tingkat sedang dan berat baru kemudian dikuti dengan meminum obat cacing.

Dalam penelitian ini, variabel ketersedian jamban, Jenis lantai rumah, Ketersidiaan air bersih, Ketersediaan tempat sampah, tidak berhubungan dengan kejadian infeksi cacing. Hal ini dimungkinkan karena terjadi bias informasi yang pada saat pengumpulan data observasi, sedangkan pada variabel kebiasaan bermain ditanah dan kebiasaan menggunakan alas kaki kemungkinan terjadi recall bias. Variabel pekerjaan ibu, pekerjaan ayah perlu penelitian korelasi ekologi. Pada variabel Jenis kelamin, kemungkinan tidak ada perbedaan jenis kelamin dalam menghindari kecacingan, misalnya prilaku kebiasaan mencuci tangan dan kaki menggunakan sabun dan kebiasaan memelihara kebersihan kuku. Untuk penelitian selanjutnya agar menganalisis hubungan jenis kelamin dengan prilaku di atas.

\section{KESIMPULAN}

Proporsi siswa yang mengalami kecacingan sebanyak 39 orang $(16,25 \%)$, jenis cacing Ascaris lumbricoide 12,91\%, jenis cacing trichuris trichuira $2,5 \%$, jenis cacing Tambang $0,83 \%$. Variabel yang mempunyai hubungan sebab akibat terhadap kejadian kecacingan pada siswa anatara lain Minum obat cacing, Kebiasaan mencuci tangan, Ketersediaan Sarana pembuangan Air Limbah (SPAL) dan Kebersihan kuku.

\section{SARAN}

Diharapkan agar orang tua memperhatikan kesehatan anaknya dengan memeriksakan anak ke sarana kesehatan, memberikan obat cacing pada anak yang posif kecacingan, memberikan contoh mencuci tangan yang benar dan mememotong kuku anaknya minimal sekali dalam seminggu. Pada pihak sekolah agar memmbuat sarana cuci tangan agar siswa dapat mempraktekkan cara cuci tangan yang benar. Kepada pihak puskesmas agar mengaktifkan kembali program kecacingan opada anak sekolah dasar.

\section{UCAPAN TERIMAKASIH}

Ucapan terimakasih ditujukan kepada Kepala Dinas Pendidikan Kota Pekanbaru, seluruh Kepala Sekolah SD Negeri Kecamatan Rumbai Pesisir Pekanbaru tempat penelitian dilakukan, Ketua Prodi Pasca Magister STIKes. Hang Tuah Pekanbaru, Prof. Dr. Buchari Lapau, dr. MPH, Dosen Pembimbing Prof. Dr. Ir. Rasoel Hamidy,MS, Ibu drg. Oktavia Dewi, M.Kes dan Ibu Tin Gustina, SKM, M.Kes yang telah banyak memberikan bimbingan dan masukan dalam penelitian ini

\section{DAFTAR PUSTAKA}

Arimbi, H. (2010). Tumbuh Kembang, Status Gizi dan Imunisasi Dasar Pada Balita, Jakarta. Nuha Medika.

Babatunde, et al (2013). Soil-Transmitted Helminthitate, Infection among School Children in Rular Communities of Moro Local Government Area, Kwara State, Nigeria, Academic Journals, vol.7 (45), pp.5184-5153, [Online] http://www.academicajournals.org diakses 14 November 2013. 
Candra, B. (2007). Pengetahuan Kesehatan Lingkungan, Jakarta: Penerbit Buku Kedokteran $E G C$.

Chin, J. ( 2012). Manual Pemberantasan Penyakit Menular,Edisi 17 Cetakan IV, Jakarta: Infomedika.

Dep.Kes RI,(2006a). DESA SIAGA Petunjuk Tenis Penyehatan Lingkungan Bagi Kader, Tokoh Masyarakat dan Petugas Pos Kesehatan Desa (POSKESDES), Jakarta.

Dep.Kes RI, (2006b) Keputusan Menteri Kesehatan Republik Indonesi No.424/MENKES/SK/VI/2006 Tentang Pedoman Pengendalian Cacingan,Jakarta,[Online] http://www.hukor.de pkes.go.id/ diakses 16 november 2013.

Fitri, J, dkk, (2012). Analisis Faktor Risiko Infeksi Kecacingan Murid Sekolah Dasar di Kecamatan Angkola Timur Kabupaten Tapanuli Selatan tahun 2012, Jurnal Ilmu Lingkungan Universitas Riau.

Ginting, A. (2009). Faktor-faktor yang berhubungan dengan kejadian kecacingan pada anak sekolah dasar di desa tertinggal Kecamatan Panguruan Kabupaten Samosir Tahun 2008, Skripsi. Fakultas Kesehatan Masyarakat Universitas Sumatera Utara Medan.

Irman, D. dkk. (2013). Higienitas kuku tangan dan infestasi Ascaris lumbricoides dan Trichuuris trichuira pada murud SD negri 40 Meranti Pandak Kecamatan Rumbai Pesisir Pekanbaru, Artikel

Penlitian,[Online] http://repository.unri.ac.id diakses 13 November 2013.

Mustakim, (2013). Hubungan sanitasi lingkungan dan perilaku anak terhadap infeksi penyakit cacingan pada anak di SDN 028 Kelurahan Madani kacamata Reteh Indragiri Hilir tahun 2013, Skripsi. StiKes Hang Tuah, Pekanbaru

Notoatmodjo,S.(2007). Kesehatan Masyarakat Ilmu \&Seni, Jakarta: Rineka Cipta.

Ratag, B.T dkk. (2012). Hubungan antara hygiene perorangan dengan infestasi nematode usus pada siswa sekolah dasar GMST Nazareth Lesa Kecamatan Tahuna Timur Kabupaten Kepulauan Sangihe, [Online ] http://www.fkm.unsrat.ac.id/ diakses 16 Desember 2013

Safar, R. (2009). Parasitologi Kedokteran Protozoologi Helmintologi Entomologi, Bandung: CV Yrama Widya.

WHO, (2013). Soil- Transmitted Helminth Infection: fact sheet No 366 updated June 2013.[Online] http://www. who.int diakses 22 November 2013.

Widodo, H. (2013). Parasitologi Kedokteran, Jogjakarta: D-MEDIKA. 